\title{
A Gene Expression Profile for Vascular Invasion can Predict the Recurrence After Resection of Hepatocellular Carcinoma: a Microarray Approach
}

\author{
Ming-Chih Ho, MD, ${ }^{1,2}$ Jen-Jen Lin, PhD, ${ }^{2,3}$ Chiung-Nien Chen, MD, PhD, ${ }^{1,2}$ Chaur-Chin \\ Chen, PhD, ${ }^{2,4}$ Hsinyu Lee, PhD ${ }^{5}$ Ching-Yao Yang, MD, ${ }^{1,2}$ Yen-Hsuan Ni, MD, PhD, ${ }^{6}$ \\ King-Jen Chang, MD, PhD, ${ }^{1,2}$ Hey-Chi Hsu, DDS, ${ }^{7}$ Fon-Jou Hsieh, MD, ${ }^{2,8}$ and \\ Po-Huang Lee, MD, PhD $^{1,2}$
}

\footnotetext{
${ }^{1}$ Department of Surgery, National Taiwan University Hospital, 7 Chung-Shan South Road, Taipei, 100, Taiwan

${ }^{2}$ Angiogenesis Research Center, National Taiwan University, Taipei, Taiwan

${ }^{3}$ Department of Applied Statistics and Information Science, Ming Chuan University, Taipei, Taiwan

${ }^{4}$ Department of Computer Science, National Tsing Hua University, Hsing Chu, Taiwan

${ }^{5}$ Department of Life Science, National Taiwan University, Taipei, Taiwan

${ }^{6}$ Department of Pediatrics, National Taiwan University Hospital, Taipei, Taiwan

${ }^{7}$ Department of Pathology, National Taiwan University Hospital, Taipei, Taiwan

${ }^{8}$ Department of Gynecology and Obstetrics, National Taiwan University Hospital, Taipei, Taiwan
}

Background: Recurrence after hepatocellular carcinoma (HCC) resection is the major obstacle to improved survival. The presence of vascular invasion (VI) in pathology specimens is a well-known unfavorable prognostic factor for HCC recurrence. Though some VI-related genes have been reported, their association with recurrence-free survival is not known. We hypothesized that a gene expression profile for VI can predict the recurrence of HCC after liver resection.

Methods: Eighteen patients receiving complete HCC resection were included as a "training group". Genome-wide gene expression profile was obtained for each tumor using a microarray technique. Datasets were subjected to clustering analysis supervised by the presence or absence of VI to obtain 14 discriminative genes. We then applied those genes to execute pattern recognition using the k-Nearest Neighbor (KNN) classification method, and the best model for this VI gene signature to predict recurrence-free survival in the training group was obtained. The resulting model was then tested in an independent "test group" of 35 patients.

Results: A 14-gene profile was extracted which could accurately separate ten patients with VI and eight patients without VI in the "training group". In the "test group", significant difference in disease-free survival was found between patients predicted to have and not to have recurrence $(P=.02823)$. In patients with stage_I disease, this model can also predict outcomes $(P=.000205)$.

Conclusions: Using the 14-gene expression profile extracted from microarrays based on the presence of VI can effectively predict recurrence after HCC resection. This approach might facilitate "personalized medicine" for HCC patients after surgical resection.

Key Words: Hepatocellular carcinoma-Microarray-Gene expression-Profiling-Vascular invasion-Liver resection-Recurrence.

Received November 7, 2005; accepted April 5, 2006; published online September 29, 2006.

Po-Huang Lee and Fon-Jou Hsieh share correspondence

Address correspondence and reprint requests to: Po-Huang Lee, MD, PhD; E-mail: pohuang@ha.mc.ntu.edu.tw

Published by Springer Science+Business Media, Inc. ㄷ 2006 The Society of Surgical Oncology, Inc.
Hepatocellular carcinoma (HCC) is one of the most common cancers in the world. In Taiwan, it is the leading cause of cancer-related deaths in humans. Without treatment, patients with HCC have a median 
survival time of 6-20 months. ${ }^{1}$ Resection provides the best chance for cure in HCC patients. With the improvement of surgical technique and peri-operative care, the surgical mortality for HCC resection can be reduced to less than 1\%., ${ }^{2,3}$ Data from the International Cooperative Study Group for HCC revealed a similar 5-year survival rate of $31-41 \%$, regardless of ethnic differences. ${ }^{4}$ However, within 5 years after liver resection, up to $80 \%$ of patients developed recurrent disease. This high cancer recurrence rate accounts for the poor survival of HCC patient after liver resection. ${ }^{5}$

To reduce the rate of early recurrence, peri-operative adjuvant therapies may be helpful. However, their efficacy needs further investigation. Ironically, some treatments have been reported to have a negative effect on patients whose prognosis is good without adjuvant therapy. ${ }^{6}$ To achieve a better outcome after HCC resection, choosing optimal peri-operative management beneficial for each individual patient is of utmost importance. Of course, this depends on the development of an effective method that can predict clinical outcome for an individual patient. Theoretically, we should give adjuvant therapy to patients who are at high risk of recurrence, while sparing those at low risk.

Clinical factors, such as vascular invasion (VI), serum $\alpha$-FP level (AFP), tumor size and tumor number, are the possible predictive factors for clinical outcomes after HCC resection. Among them, the presence of microscopic VI was recognized as the most important associated factor for early HCC recurrence. ${ }^{7-10}$ Previous reports also provided epidemiological evidence that VI has been involved in early intra-hepatic recurrence after hepatectomy for HCC. Treatments focusing on VI of HCC are under development. ${ }^{11-13}$ However, the survival advantages of these regimens are uncertain. Identifying the gene expression patterns in HCC specimens with and without VI might help to predict response to these anti-VI treatments.

VI of HCC has been reported to be associated with molecules of various biological functions. Expression of malignant hepatocyte surface CD44, which plays important roles in immune recognition, in lymphocyte trafficking, and in cell-cell and cell-matrix interactions, is related to their tendency to VI and may have implications relating to metastasis and prognosis in patients with HCCs. ${ }^{14}$ Vascular endothelial growth factor (VEGF) expression was reported to be associated with VI of HCC. ${ }^{15}$ The incidence of portal vein invasion is higher in $\mathrm{HCC}$ expressing enhancer of zeste homologue 2 (EZH2), which plays a crucial role in the regulation of embryonic development and has been associated with the regulation of the cell cycle. ${ }^{16}$ It was also suggested that p53 mutations tend to be commonly associated with microvascular invasions, which may result in micrometastases, followed by frequent recurrences. ${ }^{17}$ Expression profiles with respect to VI of HCC though have been reported; ${ }^{18,19}$ their impact on the early recurrence of HCC patients is not known. We hypothesized that a molecular signature associated with VI in HCC may serve as a surrogate marker for predicting early recurrence after HCC resection, no matter whether VI is present in the pathology examination or not.

Genome-wide gene expression analysis by microarray offers a systematic approach to unfold comprehensive information about the transcription profile of HCC. Previous studies have used microarrays to address the changes in gene expression of HCC. ${ }^{20-24}$ Our present study aimed at seeking a signature associated with VI from the genome-wide expression profile of HCC as generated from microarray study. With this signature, we tried to predict early recurrence after HCC resection. Hopefully, this will provide information for each individual patient to guide the implementation of adjuvant therapy. Thus, early recurrence after $\mathrm{HCC}$ resection can be reduced and survival prolonged.

\section{PATIENTS AND METHODS}

\section{Patients and Tissue Samples}

Eighteen consecutive patients, who received primary liver resection for $\mathrm{HCC}$ at the National Taiwan University Hospital, were included in this study as the "training group", pending good samples and good follow up. All patients underwent routine chest X-ray, abdominal ultrasound (US), computed tomography (CT) and hepatic angiography before operation. Intra-operative US was also routinely performed in all the patients. Complete tumor resection, defined as microscopically free of tumor at the section margin and no evidence of space-occupying lesions in the remnant liver as detected by image studies, were successfully performed in all the patients. No patients received any post-surgical treatment. The tumor tissue samples were collected and snap frozen in liquid nitrogen immediately after removal from the patients, under the approval of the Institutional Review Boards of National Taiwan University Hospital. Written informed consents were 
TABLE 1. Clinical and pathological characteristics in the training group

\begin{tabular}{lccc}
\hline Characteristic & $\begin{array}{c}\text { With vascular } \\
\text { invasion } \mathrm{n}=10\end{array}$ & $\begin{array}{c}\text { Without vascular } \\
\text { invasion } \mathrm{n}=8\end{array}$ \\
\hline Gender (men/women) & $8 / 2$ & $5 / 3$ & $P$ \\
Age (mean \pm SD) (years) & $51.7 \pm 15.0$ & $55.1 \pm 19.8$ & .61 \\
Viral infection (HBV/HCV/non-B, non-C) & $8 / 2 / 0$ & $4 / 3 / 1$ & $.72 \pm .40$ \\
Total bilirubin (mean \pm SD) & $.94 \pm .49$ & $50.50 \pm 27.07$ & .43 \\
Serum ALT (mean \pm SD) (IU/l) & $42.30 \pm 17.09$ & $4.16 \pm .30$ & .319 \\
Serum albumin (mean \pm SD) (g/l) & $4.35 \pm .21$ & $12.89 \pm 5.72$ & .498 \\
ICG-15 (mean \pm SD) (\%) & $16.80 \pm 12.88$ & $5 / 3$ & .197 \\
Cirrhosis (yes/no) & $8 / 2$ & $2.71 \pm 1.65$ & .631 \\
Tumor size (mean \pm SD) (cm) & $8.83 \pm 4.68$ & $0 / 8$ & .002 \\
Satellite nodules (yes/no) & $3 / 7$ & $4 / 4$ & .22 \\
Tumor grade (I $+\mathrm{II} / \mathrm{III}+\mathrm{IV})$ & $3 / 7$ & .63 \\
\hline
\end{tabular}

obtained in all participating patients. Clinical data were retrieved from their medical records. Tumor differentiation, VI, maximum tumor diameter, and non-tumor part of the removed liver were examined by an experienced pathologist without any clinical information.

The 18 patients were separated into two groups according to the presence or absence of VI as found in pathology examinations. Major VI was defined as gross invasion of the right or left main branches of the portal or hepatic veins, ${ }^{25}$ while microscopic VI was defined as the presence of tumor emboli within the central hepatic vein, the portal, or the large capsular vessels. ${ }^{9,26}$ There were ten patients who had major or microscopic VI. Another eight patients did not have any evidence of VI, either major or microscopic. All patients had solitary tumors during pathology examination. The characteristics of these patients are listed in Table 1. Early recurrence was defined as HCC recurrence diagnosed less than 1 year after surgical resection.

All the patients were followed up at our special clinic at least once every 3 months. Serum AFP and abdominal US were used as the detection methods for tumor recurrence. Abdominal CT and/or magnetic resonance imaging (MRI) were performed if the AFP was elevated or a new space-occupying lesion was detected by US. Hepatic angiography was done if $\mathrm{HCC}$ recurrence was suspected. The presence of HCC recurrence was diagnosed when a new hypervascular lesion was detected during the arterial phase of hepatic angiography.

\section{Preparation of Total RNA and PolyA RNA from HCC}

Total RNA was extracted by Trizol reagent (Invitrogen, USA) and was followed by RNeasy Mini Kit (Qiagen, Germany). The RNA isolated was quanti- fied at OD $260 \mathrm{~nm}$ and qualitatively by Bioanalyzer (Agilent Technology, USA). To serve as the reference in the cDNA microarray comparison, a human reference RNA pooled from nine cell lines (Stratagene, USA) was used. By comparison with a common reference, variation in gene expression across the samples with different clinical backgrounds could be inferred from the observed variation in the normalized $\mathrm{Cy}-3 / \mathrm{Cy}-5$ ratios across the hybridization.

\section{cDNA Synthesis, Probe Labeling and Hybridization}

The Agilent human 1 cDNA microarray (Agilent Technology) containing 18,564 spots with 13,574 different types of genes was used in this study. Fifteen micrograms of purified total RNA were converted to cDNA using a 3DNATM Array 50 Expression Array Detection Kit (Genisphere, USA). Tumor RNA was labeled with $\mathrm{Cy} 3$, and RNA from Universal Human Reference RNA was labeled with Cy5. Correspondingly synthesized cDNA products were combined and concentrated by ethanol precipitation and suspended in hybridization buffer. Hybridization of labeled cDNA was hybridized to Agilent human 1 cDNA microarray (Agilent Technologies) at $65^{\circ} \mathrm{C}$ for $17 \mathrm{~h}$. After hybridization, slides were washed in $.5 \mathrm{X} \mathrm{SSC} /$ $.01 \% \mathrm{SDS}$ at room temperature for $5 \mathrm{~min}$ and $.06 \mathrm{X}$ $\mathrm{SSC}$ at room temperature for $2 \mathrm{~min}$. Washed microarrays were then hybridized with $\mathrm{Cy} 3$ and $\mathrm{Cy} 5$ dendrimers in formamide-based buffer at $53^{\circ} \mathrm{C}$ for $3 \mathrm{~h}$. After hybridization with dendrimers, slides were washed in $2 \mathrm{X} \mathrm{SSC} / .01 \% \mathrm{SDS}$ at $42^{\circ} \mathrm{C}$ for $15 \mathrm{~min}, 2 \mathrm{X}$ $\mathrm{SSC}$ at room temperature for $10 \mathrm{~min}$, and .2X SSC at room temperature for $10 \mathrm{~min}$.

\section{Scanning and Acquisition of Image Data}

Washed microarrays were scanned with a Virtek fluorescence reader (Virtek, CA, USA) with the 
wavelengths $532 \mathrm{~nm}$ and $635 \mathrm{~nm}$ for Cy 3 and Cy 5 channels, respectively. Scanned images were analyzed by Array-Pro image acquisition software (Media Cybernetics, USA); an image analysis algorithm was used to quantify signal and background intensity for each target spot (gene). The mean intensity of the spot area was computed as the microarray raw data. The data were further analyzed with software package S-Plus 6.1 (Venables, 2002).

\section{Data Analysis}

A gene expression profile was established from the microarray raw data by a supervised learning algorithm, according to the presence or absence of VI. For each microarray chip, expression level of each gene was defined as the logarithmic ratio (base 2) of the spot expression value of the tumor sample (Cy3) to that of the common reference (Cy5). Before selecting expression genes, we needed to process the original microarray raw data to avoid the systematic error within each sample and the inconsistency of the samples.

At this preprocessing level, there were two major steps carried out on the microarray raw data. First, to avoid the systematic error within each sample, we used the rank invariant non-linear LOWESS meth$\mathrm{od}^{27,28}$ to normalize the logarithmic (with base 2) ratio of the 13,574 spot expression values. Second, to eliminate the noisy spots and the non-regulation genes, we extracted the significantly effected genes on the basis of two filtering criteria: (1) a signal-to-noise ratio (SNR) greater than 1.5 ; (2) a magnitude of normalized logarithmic ratio greater than 1 for at least five samples among the whole samples. There were 5,415 significantly effected genes extracted under these filtering criteria.

For the selection of VI-related genes, we executed statistical analysis on the 5,415 significantly effected genes extracted at the preprocessing level. First, we applied the corrected two-group multiple test ${ }^{27,29,30}$ under the .01 family-wise error rate (FWER) to extract most discriminative genes for VI. The multiple test is a method to control the probability of producing incorrect test conclusions (false positives and false negatives) for the whole gene set from original $P$ value to the adjusted $P$ value by the modified statistical algorithm. Second, to avoid the overfitting problem, we further used the leave-oneout cross-validation method ${ }^{31}$ to verify the significance of each extracted discriminative gene. The genes extracted were displayed by the supervised clustering method. ${ }^{32}$
In the training group, the tumor size was significantly bigger in patients with VI. To investigate the side effect of tumor size on the VI, at each expressed gene, we applied both analysis of variance (ANOVA) and analysis of covariance (ANCOVA) to the vascular invasion groups without or with the tumor size as the covariate. The results showed that tumor size, at each expressed gene, has no significant effect on the VI groups (all the $P$ values at covariate size were greater than .05).

\section{Confirmation of Cancer-Associated Genes by Quantitative Real-Time Reverse Transcription- Polymerase Chain Reaction}

To confirm the results of the cDNA microarray study, we performed a quantitative real-time reverse transcription-polymerase chain reaction (qRT-PCR) for the extracted genes which were reported to be associated with human malignancy. HCC total RNA extracted from $27 \mathrm{HCC}$ samples available was used for the experiment. The qPCR was carried out with a iCycler iQ Real-Time detection system (Bio-Rad, Hercules, CA, USA) with SYBR-green I (stock solution $25,000 \times$ ) as fluorescent dye enabling realtime detection of PCR products according to the manufacturer's protocol. Gene-specific primers were used (Table 2), and the specificity was confirmed by melt-curve detection following the real-time PCR reaction. Cycling conditions were $95^{\circ} \mathrm{C}$ for $3 \mathrm{~min}$, followed by 40 cycles of at $95^{\circ} \mathrm{C}$ for $30 \mathrm{~s}, 60^{\circ} \mathrm{C}$ for $30 \mathrm{~s}$ (except melanoma antigen $1,65^{\circ} \mathrm{C}$ for $30 \mathrm{~s}$ ), and $72^{\circ} \mathrm{C}$ for $30 \mathrm{~s}$. For quantification, the target gene was normalized to the internal standard gene GAPDH. Primers for real-time PCR were designed by Beacon Designer2 software (PREMIER Biosoft International, Palo Alto, CA, USA). The Pearson product moment correlation was used to show the correlation between cDNA microarray and qRT-PCR.

For prediction, the genes extracted were used to execute the pattern recognition classification method: $k$-Nearest Neighbor $(\mathrm{KNN})^{33}$ on the 18 training samples, and a prediction model was obtained. Since VI is a major factor for early HCC recurrence, a patient who has the expression profile classified into the VI-positive group is expected to have early recurrence; while a patient who has the expression profiles classified into the VI-negative group is expected not to have early recurrence. To assess the prediction power, we applied the prediction model to an independent test group of 35 patients (Table 3). The flow chart of analysis is summarized in Fig. 1. 
TABLE 2. Gene specific primers for quantitative real time reverse transcription-polymerase chain reaction in confirming the cDNA microarray results

\begin{tabular}{llcc}
\hline Primer & Sequence $\left(5^{\prime}\right.$ to $\left.3^{\prime}\right)$ & Tm $\left({ }^{\circ} \mathrm{C}\right)$ & Size \\
\hline GAPDH & F: GGT GGT CTC CTC TGA CTT CAA C & 60 & 234 bp \\
OGG1 & R: TCT CTC TTC CTC TTG TGT TCT TG & 60 & 76 bp \\
CSF3R & F: GTG CGA CTG CTG CGA CAA G & 60 & 89 bp \\
Melanoma antigen & R: TGC GGG CGA TGT TGT TGT TG & 65 & 75 bp \\
Fhrombin inhibitor & R: AGG ACT GGT TCT GAG CGT TGG & 60 & 180 bp \\
& F: ACA GGC GAG GAG GAG GAG AC & 60 \\
\hline
\end{tabular}

TABLE 3. Clinical and pathological characteristics in the test group

\begin{tabular}{|c|c|c|c|}
\hline Characteristic & With vascular invasion $\mathrm{n}=5$ & Without vascular invasion $\mathrm{n}=30$ & $P$ \\
\hline Gender (men/women) & $4 / 1$ & $24 / 6$ & 1 \\
\hline Age (mean $\pm \mathrm{SD})$ (years) & $66.4 \pm 8.7$ & $63.5 \pm 9.3$ & .56 \\
\hline Viral infection (HBV/HCV/non-B,-non-C) & $2 / 3 / 0$ & $13 / 13 / 3$ & 1 \\
\hline Total bilirubin $($ mean \pm SD) & $.65 \pm .09$ & $.83 \pm .40$ & .053 \\
\hline Serum ALT $($ mean $\pm \mathrm{SD})(\mathrm{IU} / \mathrm{l})$ & $50.00 \pm 25.00$ & $77.70 \pm 68.94$ & .143 \\
\hline Serum albumin (mean $\pm \mathrm{SD})(\mathrm{g} / \mathrm{l})$ & $4.07 \pm .23$ & $4.18 \pm .32$ & .406 \\
\hline ICG-15 (mean \pm SD) $(\%)$ & $16.86 \pm 6.87$ & $17.31 \pm 9.63$ & .910 \\
\hline Cirrhosis (yes/no) & $5 / 0$ & $23 / 7$ & .5585 \\
\hline Tumor size $($ mean $\pm \mathrm{SD})(\mathrm{cm})$ & $6.58 \pm 2.79$ & $3.64 \pm 1.86$ & .103 \\
\hline Satellite nodules (yes/no) & $1 / 4$ & $1 / 29$ & .2689 \\
\hline Tumor grade $(\mathrm{I}+\mathrm{II} / \mathrm{III}+\mathrm{IV})$ & $4 / 1$ & $24 / 6$ & 1 \\
\hline
\end{tabular}

\section{RESULTS}

Following the algorithm of our analysis, a gene profile consisting of 14 differentially expressed genes, including one putative gene, were selected. This gene profile accurately separated the eight patients with tumor VI from the ten patients with no VI, without any outliers in the training group. The heat map and name of the 14 selected genes from the 18 training samples is shown in Fig. 2. Therefore, we had generated a gene profile that can differentiate $\mathrm{HCC}$ with VI from HCC without VI in the training group.

Correlation between the expression levels of four human malignancy related genes obtained from cDNA microarray and qRT-PCR is shown in Fig. 3. Significant correlation was found in the data set of thrombin inhibitor (Pearson's correlation, $\mathrm{r}=.454$; $P=.021)$, 8-oxoguanine DNA glycosylase (Pearson's correlation, $\mathrm{r}=.469 ; P=.017)$, and melanoma antigen, family A, 9 (Pearson's correlation, $\mathrm{r}=.395 ; P=.044)$.

We then tried to predict recurrence in an independent "test group" consisting of 35 patients by using this gene profile. Pattern recognition of the cDNA microarray profile by the KNN classification method placed 26 of the 35 test samples into the category of patients that were not expected to have HCC recurrence and nine into the category that were expected to have HCC recurrence. Amount them, three of the five patients who had pathological VI were predicted to have VI by this gene set. Figure 4 shows the recurrence-free survival curves of the test group patients predicted to have recurrence (group A) and that of patients predicted not to have recurrence (group B). The HCC recurrence rate is significantly lower in group B $(P=.02823)$.

According to the AJCC pTNM staging system, not all the patients with stage _I HCC survived without early tumor recurrence. In the test group of our study, four of the 27 patients with stage_I disease had tumor recurrence within 1 year after liver resection, though no evidence of VI was found in the pathology examination of their initial tumor specimens. When our model was applied to predict the recurrence of these stage_I HCC patients, six patients were predicted to be at high risk of HCC recurrence, and 21 patients were predicted to be at low risk. The recurrence-free survival curves of these two groups of patients were significantly different and are shown in Fig. $5(P=.000205)$. 
Training samples, tumor tissue from $18 \mathrm{HCC}$ patients received primary complete

tumor resection

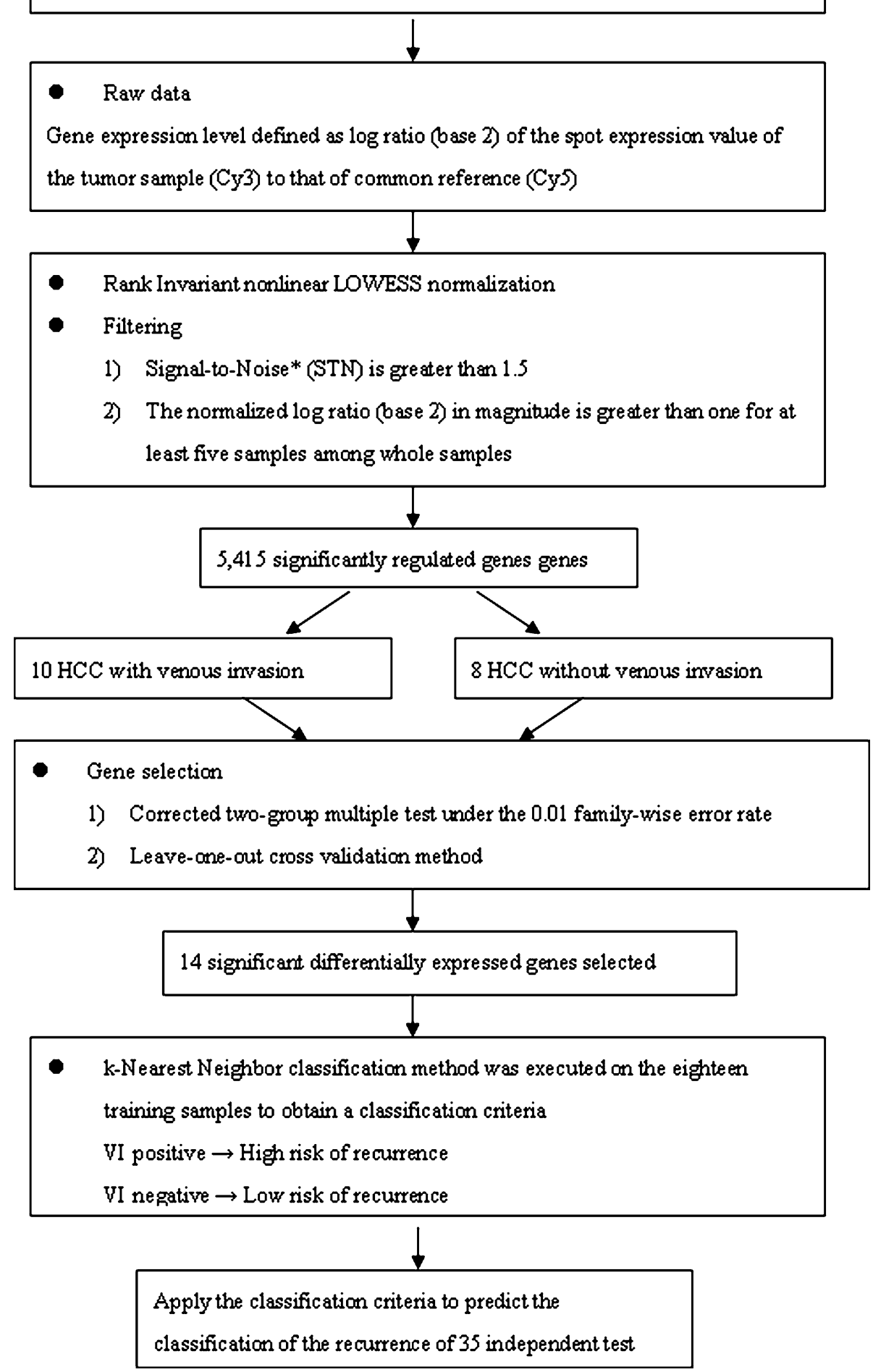

FIG. 1. Procedures for selection of differentially expressed genes and prediction: rank invariant LOWESS normalization, filtering, extraction of 5,415 regulated genes, 14 significant differentially expressed genes and KNN prediction on the test samples. 


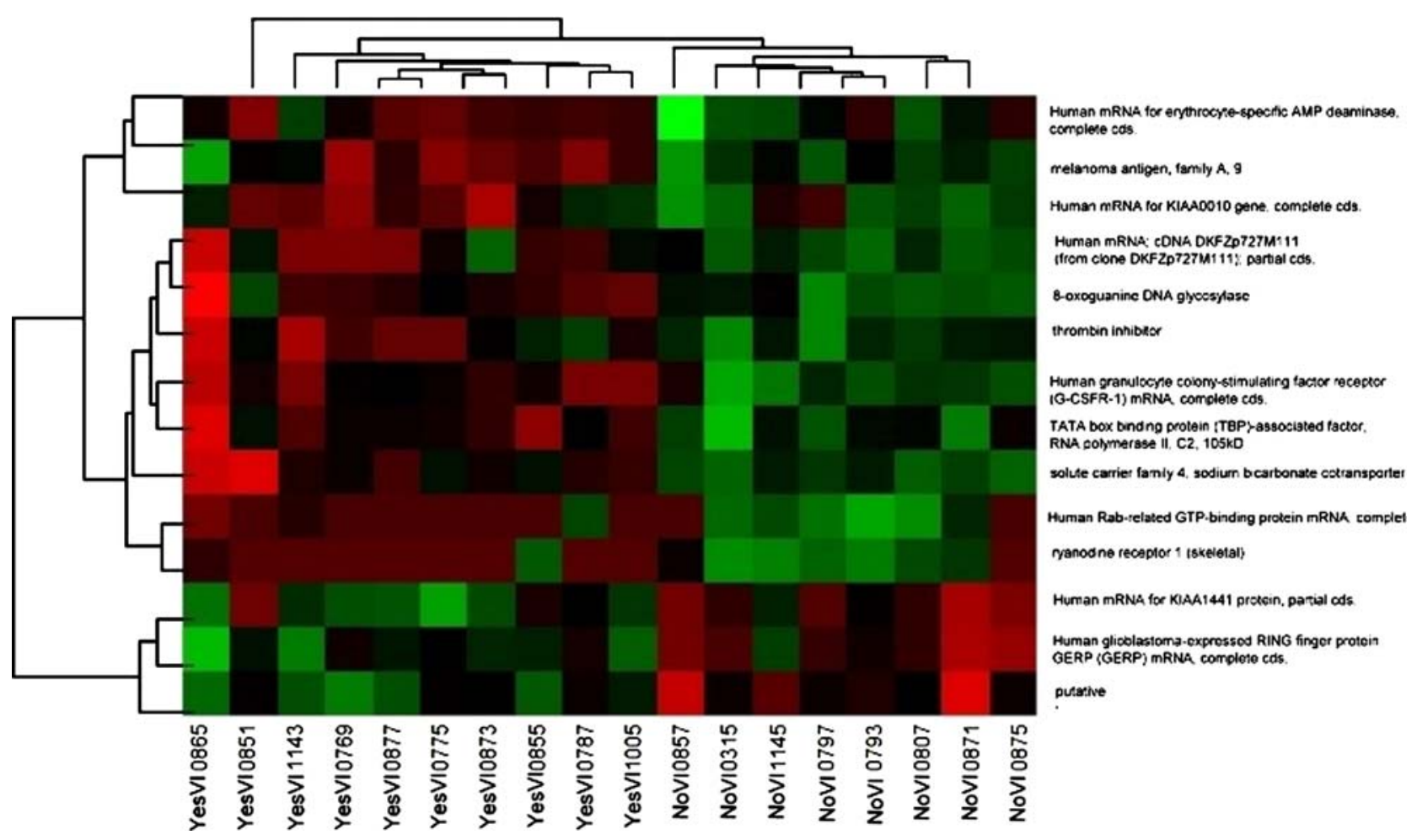

FIG. 2. Gene-expression profiles of hepatocellular carcinoma and patterns of expression of the 14 genes selected from the 18 training samples. Yes VI, presence of vascular invasion in pathology examinations, No VI, absence of vascular invasion in pathology examinations. The color display was created with the software of S plus ArrayAnalyzer1.1, which displays the average expression of all genes. Red color represents relatively high expression and green relatively low expression. The corresponding gene lists are the primary names.

\section{DISCUSSION}

Although progress of surgery and peri-operative care for HCC patients has been markedly improved, recurrence caused by intrahepatic metastasis or by metachronously multicentric carcinogenesis has become the major obstacle for better survival rate. VI has been recognized as an important step in the metastasis of HCC, and treatments focusing on VI are undergoing clinical trial. ${ }^{34,35}$ However, the survival advantages of these regimens are uncertain, though some patients experienced a rapid decline in alpha-fetoprotein level, and some patients showed shrinkage in tumor size. On the other hand, the side effects of these regimens also limit their use in the prevention of HCC recurrence. To optimize the benefits from those adjuvant therapies, accurate selection of appropriate patients is of utmost importance. A prediction system obtained from microarray studies based on the recurrence of HCC though can predict early intrahepatic recurrence with a positive predictive value of $88 \%$ and a negative predictive value of $95 \% .^{36}$ The selected genes may represent different biological characters that lead to HCC recurrence. Their implication for specific adjuvant therapy after tumor resection may be less precise. In this study, we extracted a gene signature of VI from the global gene expression profile of HCC, as generated from a cDNA microarray, and found that the extracted gene signature could effectively predict recurrence in an independent test group. Patients classified as "high risk of recurrence" are more likely to develop recurrent disease. Survival benefit from adjuvant treatments for VI may be expected in this group of HCC patients.

Other than predicting early recurrence, the multigene expression profile extracted from this microarray study may provide further insights into the complex molecular process involved in the recurrence and metastasis of HCC after surgical resection. Several genes selected from our microarray analysis have been reported to be associated with the invasiveness of human cancers. The human melanoma antigen (MAGE) gene family encodes tumor-specific antigens recognized by autologous cytotoxic $\mathrm{T}$ lymphocytes. Some of these antigens may be potentially useful for cancer-specific immunotherapy. Melanoma antigens were found to be expressed in some HCC cell lines 
(A) THIN

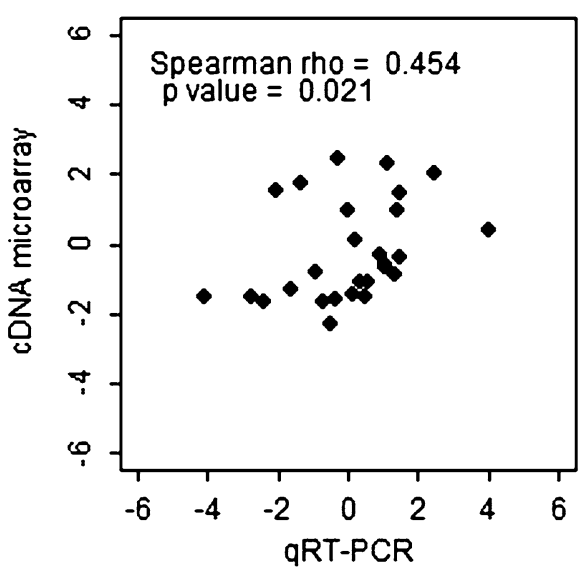

(C) MAFA

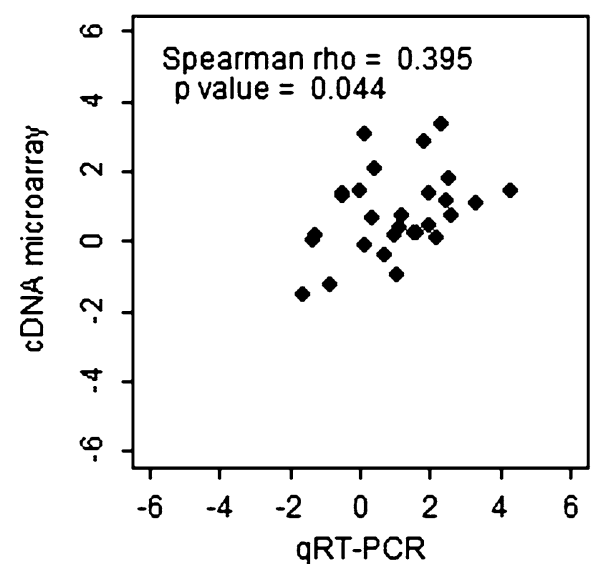

(B) OGG

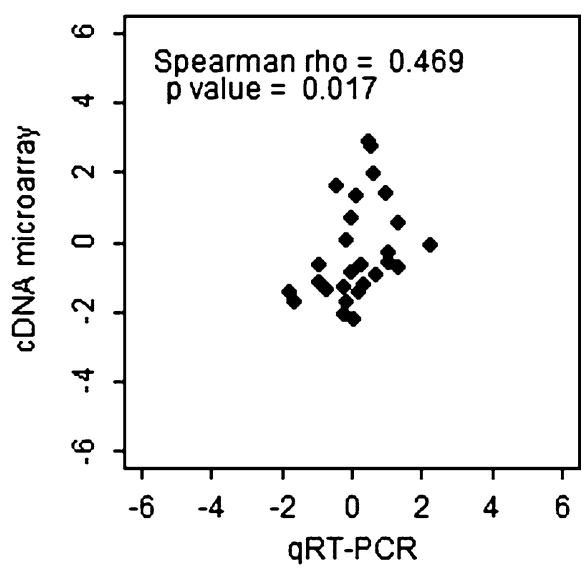

(D) CSF3R

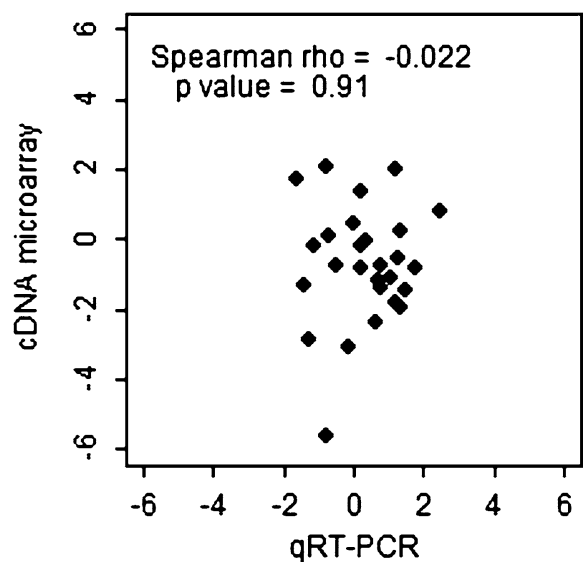

FIG. 3. Pearson's correlations between gene expression levels determined by qRT-PCR and cDNA microarray for (A) thrombin inhibitor (THIN) (B) 8-oxoguanine DNA glycosylase (OGG) (C) melanoma antigen, family A, 9 (MAFA) and (D) human granulocyte colonystimulating factor receptor (G-CSFR-1) mRNA, complete cds. (CSF3R), which were selected in this study. The mRNA levels for the gene were determined by qRT-PCR and correlated with microarray expression. All data are shown as $\log _{2}$.

but not in biopsied liver tissue. Patients with tumors expressing at least one MAGE gene showed a better recurrence-free survival rate than those with tumors showing no MAGE gene expression $(P<.05) .^{37}$ Expression of MAGE-4 was reported to be associated with the portal vein invasion of HCC. ${ }^{38}$ However, further investigation is required to elucidate those correlations completely. Formation of 8-hydroxydeoxyguanine $(8-\mathrm{OHdG})$ is one of the most common types of oxidative DNA damage, while human oxoguanine glycosylase 1 (hOGG1) is responsible for repairing 8-OHdG lesions. Previous study suggested that patients with atrophic gastritis in conjunction with the hOGG1 Cys allele might have a higher susceptibility to gastric cancer. ${ }^{39}$ OGG1 R154H may function as a low/moderate-penetrance modifier for colorectal cancer development. ${ }^{40}$ hOGG1 Ser326Cys polymorphism also plays an important role in the risk for lung cancer and is linked to exposure to tobacco smoke. ${ }^{41}$ Loss of hOGG1 expression may have a role in the development or progression of CC-RCC. ${ }^{42}$

Thrombin is a potent mitogen for many tumor cells, suggesting that this enzyme may be involved in tumor genesis and metastasis. ${ }^{43}$ Thrombin appears to contribute to tumor cell dissemination through at least one fibrinogen-independent mechanism. ${ }^{44}$ Thrombin present in the lungs of patients with pulmonary metastasis is, at least in part, responsible for their adhesive, invasive and mitogenic activity. ${ }^{45}$ Inhibition of thrombin expressed on the surface of tumor cells may improve outcomes in some tumor cases. Human granulocyte colony-stimulating factor 


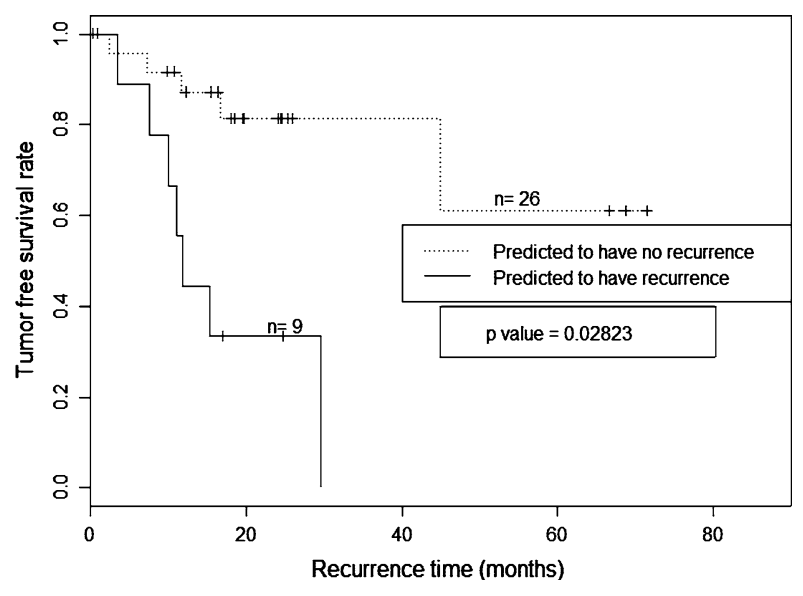

FIG. 4. For the test group as a whole the recurrence rate of the patients predicted to have recurrence by our gene expression signature was significantly higher than that of patients predicted not to have recurrence $(P=.02823)$.

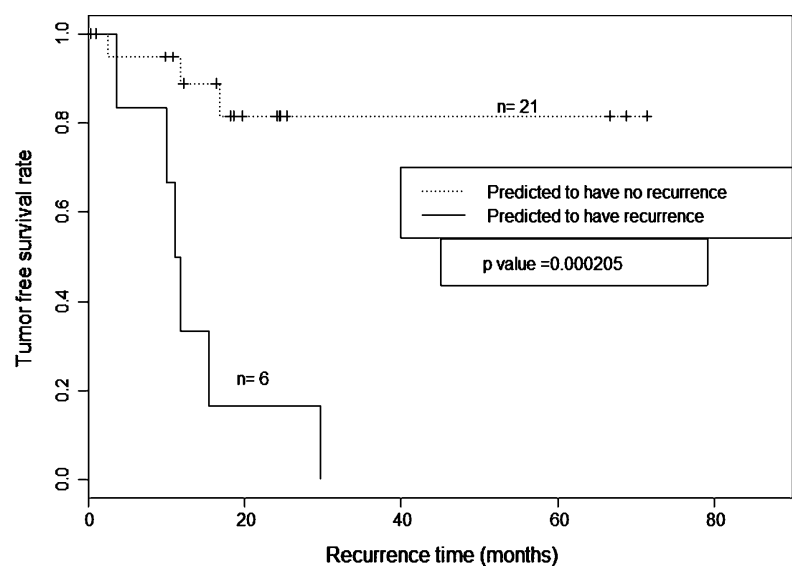

FIG. 5. The recurrence rate of AJCC pTNM stage_I patients predicted to have recurrence was significantly higher than that of stage_I patients predicted not to have recurrence $(P=.000205)$.

receptor (G-CSFR-1) expression increases beta 1-integrin expression and adhesion and, thereby, may promote tissue invasion of some bladder cancers. ${ }^{46}$ The other genes selected included AMPD3, which is involved in biosynthesis processes in human liver and muscle; TAF4B, which regulates expression of genes controlling cell proliferation ${ }^{47}$; SLC4A7, RAB38 and RYR1, which are related to cell growth; KIAA0010, DKFZP727M111, KIAA1441 and TRIM8, whose biological functions are not well known; and a putative gene.

In the training group (Table 1), tumors lacking vascular invasion had a mean diameter of $2.71 \mathrm{~cm}$ compared with tumors with vascular invasion of $8.83 \mathrm{~cm}$ diameter $(P=.002)$. This presence of VI may generally reflects a later stage of tumor progression and, therefore, also a worse outcome. However, some "early HCCs" still recur early after resective surgery. Tumors with identical histopathologies may progress differently, respond differently to therapy, and may be associated with different clinical prognoses, suggesting that additional parameters should be identified to predict disease outcomes. ${ }^{48,49}$ We believe that some tumors are programmed to have vascular invasion while others are not and that VI is not simply a progression of tumor growth. This is supported by the fact that VI still presents in HCCs when they are less than $2 \mathrm{~cm}$, and it is an independent prognostic factor for survival under multivariate analysis. ${ }^{50}$ Also in this study, our model could not only discriminate the survival of 35 independent patients as a whole but was also helpful in separating AJCC stage_I patients into groups with different disease-free survival. This implies that negative vessel invasion, as revealed by pathology examination, cannot precisely reflect the behavior of an early HCC.

Traditional methods of testing for cancer require $10,000-100,000$ abnormal cells in order to work. The metastasis of tumor cells into the portal venous flow cannot be detected microscopically. Detection of tumor-associated antigens, such as MAGE, alphafetoprotein and/or mRNA, or cancer cells in the blood stream has been reported to predict the tumor invasiveness and recurrence of HCC after liver resection. ${ }^{51-54}$ However, the predictive power is not quite satisfactory. A tumor with metastatic potential may spread early during its growth. This can usually be detected neither by pathology examination nor by the molecular methods reported. The prediction model developed in the present study might be able to serve as a complementary tool, providing useful information to predict disease outcome in early HCC patients and guiding adjuvant therapy. Our approach, although far from perfect, might be the first step in the implementation of personalized medicine for HCC patients after surgical resection.

In conclusion, we have developed a prediction model for the VI of HCC based on genome-wide microarray study. This 14-gene expression profile can effectively predict the recurrence after surgical resection for HCC. The patients classified as VI positive or at high risk of recurrence should be followed up more closely for recurrence, and they may be the subjects who will benefit from the future effective adjuvant treatment now under development. Also, this strategy for stratification of HCC patients after surgical resection might provide an avenue to more rational 
clinical trials for HCC post-operative adjuvant therapy in the future. Hopefully, this multigene profile will offer further insights into the extremely complex molecular process of cancer recurrence.

\section{ACKNOWLEDGMENTS}

We thank Dr. Yi-Shing Lin of Welgene Co. for technical assistance. This project was supported by a grant from the Department of Industrial Technology, Ministry of Economic Affairs, Taiwan

\section{REFERENCES}

1. Barbara L, Benzi G, Gaiani S, et al. Natural history of small untreated hepatocellular carcinoma in cirrhosis: a multivariate analysis of prognostic factors of tumor growth rate and patient survival. Hepatology 1992; 16:132-7.

2. Fan ST, Lo CM, Liu CL, Lam CM, Yuen WK, Yeung C, Wong J. Hepatectomy for hepatocellular carcinoma: toward zero hospital deaths. Ann Surg 1999; 229:322-30.

3. Imamura H, Seyama Y, Kokudo N, et al. One thousand fiftysix hepatectomies without mortality in 8 years. Arch Surg 2003; 138:1198-1206.

4. Esnaola N, Mirza N, Lauwers G, et al. Comparison of clinicopathologic characteristics and outcomes after resection in patients with hepatocellular carcinoma treated in the United States, France, and Japan. Ann Surg 2003; 238:7119.

5. Jaeck D, Bachellier P, Oussoultzoglou E, Weber JC, Wolf P. Surgical resection of hepatocellular carcinoma. Post-operative outcome and long-term results in Europe: an overview. Liver Transpl 2004; 10(2 Suppl 1):S58-63.

6. Sun HC, Tang ZY. Preventive treatments for recurrence after curative resection of hepatocellular carcinoma - a literature review of randomized control trials. World $J$ Gastroenterol 2003; 9:635-40.

7. Imamura H, Matsuyama Y, Tanaka E, et al. Risk factors contributing to early and late phase intrahepatic recurrence of hepatocellular carcinoma after hepatectomy. J Hepatol 2003; 38:200-7.

8. Hanazaki K, Kajikawa S, Koide N, Adachi W, Amano J. Prognostic factors after hepatic resection for hepatocellular carcinoma with hepatitis $\mathrm{C}$ viral infection: univariate and multivariate analysis. Am J Gastroenterol 2001; 96:1243-50.

9. Vauthey JN, Lauwers GY, Esnaola NF, et al. Simplified staging for hepatocellular carcinoma. J Clin Oncol 2002; 20:1527-36.

10. Yamanaka J, Yamanaka N, Nakasho K, et al. Clinicopathologic analysis of stage II-III hepatocellular carcinoma showing early massive recurrence after liver resection. $J$ Gastroenterol Hepatol 2000; 15:1192-8.

11. Kaneko S, Urabe T, Kobayashi K. Combination chemotherapy for advanced hepatocellular carcinoma complicated by major portal vein thrombosis. Oncology 2002; 62(Suppl 1):6973.

12. Xia JL, Yang BH, Tang ZY, Sun FX, Xue Q, Gao DM. Inhibitory effect of the angiogenesis inhibitor TNP-470 on tumor growth and metastasis in nude mice bearing human hepatocellular carcinoma. J Cancer Res Clin Oncol 1997; 123:383-7.

13. Patt YZ, Hassan MM, Lozano RD, Brown TD, Vauthey JN, Curley SA. Ellis LM. Phase II trial of systemic continuous fluorouracil and subcutaneous recombinant interferon Alfa- $2 b$ for treatment of hepatocellular carcinoma. J Clin Oncol 2003; 21:421-7.

14. Mathew J, Hines JE, Obafunwa JO, Burr AW, Toole K, Burt AD. CD44 is expressed in hepatocellular carcinomas showing vascular invasion. J Pathol 1996; 179:74-79.

15. Deli G, Jin CH, Mu R, Yang S, Liang Y, Chen D, Makuuchi M. Immunohistochemical assessment of angiogenesis in hepatocellular carcinoma and surrounding cirrhotic liver tissues. World J Gastroenterol 2005; 11:960-3.

16. Sudo $T$, Utsunomiya $T$, Mimori $K$, et al. Clinicopathological significance of EZH2 mRNA expression in patients with hepatocellular carcinoma. Br J Cancer 2005; 92:1754 8.

17. Park NH, Chung YH, Youn KH, et al. Close correlation of p53 mutation to microvascular invasion in hepatocellular carcinoma. J Clin Gastroenterol 2001; 33:397-401.

18. Okabe H, Satoh S, Kato T, et al. Genome-wide analysis of gene expression in human hepatocellular carcinomas using cDNA microarray: identification of genes involved in viral carcinogenesis and tumor progression. Cancer Res 2001; 61:2129-37.

19. Chen X, Cheung ST, So S, et al. Gene expression patterns in human liver cancers. Mol Biol Cell 2002; 13:1929-39.

20. Honda M, Kaneko S, Kawa H, Shirota Y, Kobayashi K. Differential gene expression between chronic hepatitis B and C hepatic lesion. Gastroenterology 2001; 120:955-66.

21. Shirota Y, Kaneko S, Honda M, Kawai HF, Kobayashi K. Identification of differentially expressed genes in hepatocellular carcinoma with cDNA microarrays. Hepatology 2001; 33:83240.

22. Tackels-Horne D, Goodman MD, Williams AJ, et al. Identification of differentially expressed genes in hepatocellular carcinoma and metastatic liver tumors by oligonucleotide expression profiling. Cancer 2001; 92:395-405.

23. Xu L, Hui L, Wang $\mathrm{S}$, et al. Expression profiling suggested a regulatory role of liver-enriched transcription factors in human hepatocellular carcinoma. Cancer Res 2001; 61:31763181.

24. Xu X-R, Huang J, Xu Z-G, et al. Insight into hepatocellular carcinogenesis at transcriptome level by comparing gene expression profiles of hepatocellular carcinoma with those of corresponding noncancerous liver. Proc Natl Acad Sci U S A 2001; 98:15089-94.

25. Hermanek P, Hendson DE, Hutter RVP. TNM supplement 1993: a commentary on uniform use Berlin: Springer; 1993.

26. Ikai I, Yamamoto Y, Yamamoto N, Terajima H, Hatano E, Shimahara Y, Yamaoka Y. Results of hepatic resection for hepatocellular carcinoma invading major portal and/or hepatic veins. Surg Oncol Clin N Am 2003; 12:65-75.

27. Yang YH, Dudoit S, Luu P, Lin DM, Peng V, Ngai J, Speed TP. Normalization for cDNA microarray data: a robust composite method addressing single and multiple slide systematic variation. Nucleic Acids Res 2002; 30:e15.

28. Tseng GC, Oh MK, Rohlin L, Liao JC, Wong WH. Issues in cDNA microarray analysis: quality filtering, channel normalization, model of variations and assessment of gene effects. Nucleic Acids Res 2001; 29:2549-57.

29. Hochberg Y, Tamhane AC. Multiple comparison procedures New York: Wiley; 1987.

30. Westfall PH, Young SS. Resampling-based multiple testing: examples and methods for P-value adjustment New York: Wiley; 1993.

31. van't Veer LJ, Dai H, van de Vijver MJ, et al. Gene expression profiling predicts clinical outcome of breast cancer. Nature 2002; 415:530-6.

32. Eisen MB, Spellman PT, Brown PO, Botstein D. Cluster analysis and display of genome-wide expression patterns. Proc Natl Acad Sci USA 1998; 95:14863-8.

33. Cover TM, Hart PE. "Nearest Neighbor Pattern Classification," IEEE Trans Inf Theory 1967; IT-13, 21-27. 
34. Patt YZ, Hassan MM, Lozano RD, Ellis LM, Peterson JA, Waugh KA. Durable clinical response of refractory hepatocellular carcinoma to orally administered thalidomide. Am J Clin Oncol 2000; 23:319-21.

35. Hsu C, Chen CN, Chen LT, et al. Low-dose thalidomide treatment for advanced hepatocellular carcinoma. Oncology 2003; 65:242-9.

36. Iizuka N, Oka M, Yamada-Okabe $\mathrm{H}$, et al. Oligonucleotide microarray for prediction of early intrahepatic recurrence of hepatocellular carcinoma after curative resection. Lancet 2003; 361:923-9.

37. Suzuki K, Tsujitani S, Konishi I, Yamaguchi Y, Hirooka Y, Kaibara N. Expression of MAGE genes and survival in patients with hepatocellular carcinoma. Int J Oncol 1999; 15:1227-32.

38. Tahara K, Mori M, Sadanaga N, Sakamoto Y, Kitano S, Makuuchi M. Expression of the MAGE gene family in human hepatocellular carcinoma. Cancer 1999; 85:1234-40.

39. Tsukino H, Hanaoka T, Otani T, et al. hOGG1 Ser326Cys polymorphism, interaction with environmental exposures, and gastric cancer risk in Japanese populations. Cancer Sci 2004; 95:977-983.

40. Kim IJ, Ku JL, Kang HC, et al. Mutational analysis of OGG1, MYH, MTH1 in FAP, HNPCC and sporadic colorectal cancer patients: R154H OGG1 polymorphism is associated with sporadic colorectal cancer patients. Hum Genet 2004; 115:498503.

41. Park J, Chen L, Tockman MS, Elahi A, Lazarus P. The human 8-oxoguanine DNA N-glycosylase 1 (hOGG1) DNA repair enzyme and its association with lung cancer risk. Pharmacogenetics 2004; 14:103-9.

42. Mukunyadzi P, Huang H, Liu K, Fan CY. Concomitant loss of mitochondria and the DNA repair protein hOGG1 in clear cell carcinoma of the kidney. Appl Immunohistochem Mol Morphol 2003; 11:334-38.

43. Nierodzik ML, Kajumo F, Karpatkin S. Effect of thrombin treatment of tumor cells on adhesion of tumor cells to platelets in vitro and tumor metastasis in vivo. Cancer Res 1992; $52: 3267-72$.

44. Palumbo JS, Degen JL. Fibrinogen and tumor cell metastasis. Haemostasis 2001; 31(Suppl 1):11-15.
45. Hernandez-Rodriguez NA, Correa E, Contreras-Paredes A, Green L. Evidence that thrombin present in lungs of patients with pulmonary metastasis may contribute to the development of the disease. Lung Cancer 1999; 26:157-67.

46. Chakraborty A, White SM, Lerner SP. Granulocyte colonystimulating factor receptor signals for betal-integrin expression and adhesion in bladder cancer. Urology 2004; 63:177183.

47. Mengus G, Fadloun A, Kobi D, Thibault C, Perletti L, Michel I, Davidson I. TAF4 inactivation in embryonic fibroblasts activates TGF beta signalling and autocrine growth. EMBO J 2005; 24:2753-67.

48. Macoska JA. The progressing clinical utility of DNA microarrays. CA Cancer J Clin 2002; 52:50-9.

49. Wilkens L, Bredt M, Flemming P, Mengel M, Becker T, Klempnauer J, Kreipe H. Comparative genomic hybridization $(\mathrm{CGH})$ and fluorescence in situ hybridization (FISH) in the diagnosis of hepatocellular carcinoma. $J$ Hepatobiliary Pancreat Surg 2002; 9:304-11.

50. Fukuda S, Itamoto T, Nakahara H, et al. Clinicopathologic features and prognostic factors of resected solitary small-sized hepatocellular carcinoma. Hepatogastroenterology 2005; 52:1163-7.

51. Ijichi M, Takayama T, Matsumura M, Shiratori Y, Omata M, Makuuchi M. Alpha-fetoprotein mRNA in the circulation as a predictor of postsurgical recurrence of hepatocellular carcinoma: a prospective study. Hepatology 2002; 35:853-860.

52. Witzigmann H, Geissler F, Benedix F, et al. Prospective evaluation of circulating hepatocytes by alpha-fetoprotein messenger RNA in patients with hepatocellular carcinoma. Surgery 2002; 131:34-43.

53. Mou DC, Cai SL, Peng JR, et al. Evaluation of MAGE-1 and MAGE-3 as tumour-specific markers to detect blood dissemination of hepatocellular carcinoma cells. Br J Cancer 2002; $86: 110-16$

54. Waguri N, Suda T, Nomoto M, et al. Sensitive and specific detection of circulating cancer cells in patients with hepatocellular carcinoma; detection of human telomerase reverse transcriptase messenger RNA after immunomagnetic separation. Clin Cancer Res 2003; 9:3004-11. 